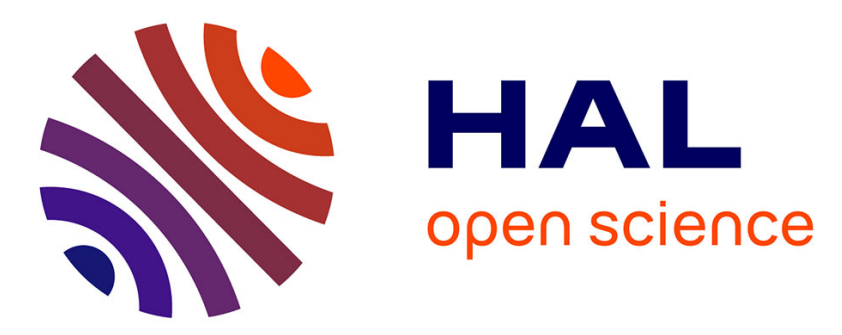

\title{
Income Redistribution and Public Good Provision: An Experiment
}

\author{
Jonathan Maurice, Agathe Rouaix, Marc Willinger
}

\section{To cite this version:}

Jonathan Maurice, Agathe Rouaix, Marc Willinger. Income Redistribution and Public Good Provision: An Experiment. International Economic Review, 2013, 54 (3), pp.957-975. 10.1111/iere.12024 . hal-00859478

\section{HAL Id: hal-00859478 \\ https://hal.science/hal-00859478}

Submitted on 12 Nov 2019

HAL is a multi-disciplinary open access archive for the deposit and dissemination of scientific research documents, whether they are published or not. The documents may come from teaching and research institutions in France or abroad, or from public or private research centers.
L'archive ouverte pluridisciplinaire HAL, est destinée au dépôt et à la diffusion de documents scientifiques de niveau recherche, publiés ou non, émanant des établissements d'enseignement et de recherche français ou étrangers, des laboratoires publics ou privés. 


\title{
Income Redistribution And Public Good PROVISION: AN EXPERIMENT*
}

Jonathan MAURICE
Agathe Rouaix

Marc WiLLingeR ${ }^{1}$

\begin{abstract}
We investigate experimentally the impact of income redistribution on voluntary contributions by groups of four subjects. We compare equalizing and unequalizing redistribution. Our data are consistent with the neutrality theorem: redistribution does not affect the amount of voluntarily provided public good at the group level. However at the individual level, subjects tend to under-adjust with respect to the Nash-prediction. We also observe an insignificant adjustment asymmetry between the poor and the rich: subjects who become poorer adjust their contribution by a larger absolute amount than subjects who become richer. Finally, poor subjects tend to over-contribute significantly more than rich subjects.
\end{abstract}

Shortened title: Redistribution and Public Good

JEL: H3, C9, H41

Keywords: redistribution, voluntary provision, public good, inequality, social dilemma

\section{Introduction}

A common argument for the defense of income privileges is that they allow the provision of public goods not provided by States. It is typically the case for arts patronage provided by

\footnotetext{
*Manuscript received August 2011; revised March 2012.

${ }^{1}$ The authors acknowledge financial support received from the Agence nationale de la recherche through the research program "Conflict and inequality," ref. ANR-08-JCJC-0105-01, and from the Institut universitaire de France.

We are specially indebted towards Charles Figuières who helped us at various stages of this project through helpful discussions and in-depth readings. We thank Mickael Beaud, Sascha O. Becker, Friedrich Bolle, Dimitri Dubois, Jean Hindriks, Karl Schlag and three anonymous referees for their helpful comments for improving the paper. Also we like to thank participants at several conferences and seminars for helpful suggestions. The usual disclaimer applies.
} 
a few foundations funded by very high income people, and more broadly for donations to charities. It can therefore be argued that privileges and income inequalities could be preserved to maintain this provision and to compensate for some state failures. This argument runs clearly against the redistributive role of the State. But is it relevant? Will reducing income inequalities between donors to charities really decrease the global amount of donations and more generally lead to a lesser provision of public goods?

Economic theory provides a rather straightforward answer to this question. In many cases the reallocation of resources between agents is neutral with respect to the collective effort of public good provision. Warr (1983) demonstrated that a redistribution of income has no effect on the private provision of a public good when a single public good is provided (positively) by private individuals. His "neutrality theorem" was extended to non-infinitesimal variations and to other cases by Bergstrom, Blume and Varian (1986), BBV hereafter. Basically neutrality holds because individuals who are richer after redistribution compensate the reduced contribution to the public good of individuals who are poorer.

These theoretical findings raise interesting questions from a behavioral point of view. Is it the case that individuals who become richer increase their contributions, and individuals who become poorer decrease it? And if true, to what extent do these adjustments cancel out so that neutrality holds? This paper aims at providing answers to these questions. We design an experiment based on a voluntary contribution game in which we implement a redistribution of the group endowment ${ }^{2}$ after an initial sequence of periods of voluntary contributions. The data allow us to investigate the relevance of the neutrality property pointed out in Warr's paper and, beyond, to understand how subjects react to redistribution. Precisely, is it the case that groups of subjects react to an equalizing redistribution in the same way as they react to an unequalizing redistribution? And is it the case that subjects who get poorer (richer) in an equalizing society adjust their level of contribution by the same amount than subjects who get poorer (richer) in an unequalizing society?

In the experiment the voluntary contribution game is played in groups of four subjects. The constituent game has a unique interior dominant strategy equilibrium and is repeated in sequences of 10 periods. Each of our four treatments consists of two sequences which

\footnotetext{
${ }^{2}$ In the rest of the paper we use indifferently the words income or endowment.
} 
can differ with respect to the endowment distribution. The test treatments involve either an unequalizing or an equalizing redistribution. In the unequalizing redistribution treatment the first sequence involves an equal endowment distribution while in the second sequence there are two "rich" and two "poor" subjects. In the equalizing redistribution treatment the ordering of these two sequences is reversed. These two test treatments are compared to benchmark treatments in which the endowment distribution-equal or unequal-remains unchanged over the two sequences. Of course, the total group endowment remains constant across treatments.

Our main findings can be summarized as follows: i) redistribution does not affect the average amount of public good provided, in accordance with the neutrality theorem of Warr (1983) and BBV (1986), ii) subjects who become richer after redistribution tend to underadjust, i.e. they increase their contribution but less than predicted, and iii) poor subjects tend to over-contribute with respect to their Nash-contribution while rich subjects contribute at their Nash level. We also observe that after redistribution subjects who become poorer lower their contribution by a larger amount than subjects who become richer increase their contribution. However, this asymmetry is not enough pronounced to be significant.

The rest of the paper is organized as follows. In section 2 we present the theoretical models of Warr (1983) and BBV (1986) and their testable predictions. Previous experiments are presented in section 3. Section 4 introduces our experimental design. In section 5 we present our results and section 6 discusses them. Section 7 concludes.

\section{The neutrality theorem}

Two fundamental papers deal with the effect of income redistribution on voluntary contributions to a public good. Warr (1983) concludes under quite general assumptions that "[w] hen a single public good is provided at positive levels by private individuals, its provision is unaffected by a redistribution of income." BBV (1986) extend this result to non-infinitesimal variations of income.

Warr's (1983) result applies when "individuals behave as atomistic utility maximizers in the determination of their provision of a single public good, and where this result is an 
interior solution to their utility maximization problem." We provide a brief sketch of the model, underlying the central hypotheses, in order to justify the choices for our experimental design. The model assumes $n$ consumers and $m$ private goods. There is a single public good, the amount of which is noted $g=\sum_{i=1}^{n} g_{i}$ where $g_{i}$ is the private contribution by agent $i$. Agent $i$ 's utility function is given by $u_{i}\left(x_{i}, g\right)$ where $x_{i}$ is his consumption of private goods. ${ }^{3}$ The model assumes that each individual behaves as a selfish utility maximizer. A key property is that each individual contributes a strictly positive amount to the public good, i.e. the solution of the maximization program admits a unique interior solution.

The Nash-equilibrium corresponds to a level of public good provision that is inferior to the Pareto-optimal level. Let $w_{i}$ be the exogenous income for agent $i, p$ the price vector of private goods and $q$ the price of the public good. Warr shows that the aggregate demand function for the public good depends only on $p, q$ and $w$ (where $w$ is aggregate income, $w=\sum_{i=1}^{n} w_{i}$ ), but not on the distribution of income. In other words, whatever the income distribution, as long as aggregate income is unchanged, the amount of public good will be constant. Identically the result can be restated in terms of aggregate demands for private goods. The latter are functions of $p, q$ and $w$. Since only aggregate income matters, as demonstrated by Warr, any redistribution generates the same demands for private goods. The intuition behind the result is that agents maximise their utility by choosing optimally their level of consumption of private goods. Their contribution to the public good is therefore "residual." An agent who becomes richer after redistribution spends his extra-income by increasing his contribution to the public good by the same amount. In contrast, an agent who becomes poorer will cut his contribution by the exact amount of his income reduction. As far as his private consumption is not affected by his income reduction, the reduced contribution by the poor is perfectly offset by the increased contribution of the rich. Furthermore, each individual has exactly the same level of utility before and after income redistribution.

This result holds despite preference heterogeneity in the group of agents in the form of heterogeneous marginal propensities to contribute to the public good and depends crucially on the following assumptions: i) each agent contributes strictly positively to the public good before the redistribution occurs, ii) he consumes at least one private good, and iii) variations

\footnotetext{
${ }^{3} u_{i}\left(x_{i}, g\right)$ is strictly quasi-concave, twice differentiable and increasing in all arguments.
} 
of income are infinitesimal.

BBV (1986) considered the more general case where redistribution of income implies noninfinitesimal variations of income. Their main new assumption is that the redistribution of income among the contributing agents does not lead - at individual level - to losses that are larger than the original contribution for each consumer. If this assumption is satisfied and consumers' preferences are convex, "each consumer consumes the same amount of the public good and the private good that he did before the redistribution" (BBV, 1986: 29, theorem 1). They only insist on one restriction on this neutrality result. "The result is sensitive to the assumption that utility depends only on private consumption and the amount of the public good" (BBV, 1986: 31). If other arguments are introduced, the neutrality theorem will not apply for all functional forms of utility.

\section{Previous experiments}

Since our experimental setting involves asymmetric endowment distributions, it is useful to start with a review of the experimental literature on endowment inequality in public good games. The effects of endowment heterogeneity on contributions are quite mixed. Isaac and Walker (1988) found that groups with asymmetric endowments contribute less to the public good than groups with symmetric endowments. At individual level Buckley and Croson (2006) observed that subjects with low endowments contribute the same absolute amount to a (linear) public good than subjects with high endowment, implying that poor contribute more in relative terms (see also Hofmeyer et al., 2008). Chan et al. (1999) studied the effects of endowment and preference heterogeneity on group contribution to a (non-linear) public good, under alternative conditions of information and communication. They found that heterogeneity increases contributions to the public good. Finally, based on a metaanalysis Zelmer (2003) estimated a significantly negative impact of endowment heterogeneity on contributions.

The most relevant paper is however Chan et al. (1996) who investigated Warr's (1983) and BBV's (1986) predictions based on a between-subject experiment. Groups of three subjects faced different endowment distributions, ranging from low to high inequality, keeping the 
aggregate endowment constant. The experiment consisted in five treatments: a benchmark (equality) treatment where subjects had the same endowment, and four inequality treatments involving two poor subjects and one rich subject. When focusing on the two low inequality treatments for which the authors predicted neutrality as in Warr, their findings are consistent with our results. However their experimental design suffers from several limitations that may cast doubt about the results and which we therefore tried to overcome in our experiment.

First, their parametric setting generated multiplicity of Nash-equilibria. While the game has a unique Nash-level of group contribution, it is compatible with several Nash-contribution vectors. Specifically both in the benchmark and in one of the inequality treatments, the unique group Nash-contribution was compatible with seven different contribution vectors (three in the other inequality treatments). ${ }^{4}$ Because of such multiplicity of Nash equilibria in individual contributions, the coordination issue might have affected subjects' choices in an unpredictable way, or might have confused some of them.

Second, their experiment actually compared contributions by groups with homogeneous endowments to contributions by groups with heterogeneous endowments, in contrast to our experiment in which we performed a real redistribution within groups. While both experimental procedures have the same underlying theoretical framework, the descriptions proposed in Warr (1983) and BBV (1986) addressed explicitly the issue of redistribution. We believe that our experimental setting is therefore closer in spirit to the theoretical literature. Furthermore, if subjects' decisions are partly the outcome of unobservable individual characteristics, it is preferable to rely on a within-subject comparison rather than on a between-subject comparison, since the former provides a better control. If each subject is exposed both to an unequal and an equal endowment distribution unobservable individual characteristics are kept constant across treatments. Finally, the within-subject framework allows also to perform exactly the same type of comparison than the between-subject framework since before redistribution each subject/group faces some initial endowment distribution. Since redistri-

\footnotetext{
${ }^{4}$ Since player $i$ 's utility is given by $u_{i}\left(x_{i}, g\right)=x_{i}+g+x_{i} g$, his best reply is to contribute $g_{i}=\max \left(\frac{w_{i}-g_{-i}}{2}, 0\right)$. The unique group Nash-contribution is $g^{*}=\sum_{i=1}^{n} g_{i}^{*}=15$ but individual Nashcontributions must satisfy $4 \leq g_{i}^{*} \leq 5$ for $i=1,2,3$ for the benchmark treatment, and $2 \leq g_{i}^{*} \leq 4$ for $i=1,2$, and $8 \leq g_{3}^{*} \leq 10$ for the low inequality treatments.
} 
bution is not announced at the beginning of the experiment, varying the initial distributions across groups allows us to compare the contribution of groups with homogeneous versus heterogeneous endowment distribution as in Chan et al. (1996). But additionally, we are also able to observe the impact of redistribution as such, all things being equal. We are aware of only one other experimental paper that implemented redistribution (Uler, 2011). As in our experiment, Uler (2011) adopts a within-subject design that allows him to compare the impact on contributions of equal and unequal endowment distribution both within and between subjects. But in contrast to our setting Uler (2011) considered ex post redistribution through a tax levied on net income after contribution, and did not address the issue of neutrality. Rather his paper concentrates on the issue of ex ante versus ex post inequality.

\section{Experimental design}

In this section we describe our experimental design by presenting the underlying game, the practical procedures that were implemented in the lab and the treatments that we chose for testing the neutrality theorem.

Our experimental design captures the key hypotheses of Warr (1983) and BBV (1986), and prevents the coordination issue raised by multiple equilibria in individual contributions as in Chan et al. (1996). Furthermore we allow for a direct test of redistribution in the spirit of Warr (1983) and BBV (1986).

\subsection{The contribution game}

We follow standard experimental procedures for designing the contribution game. In each period of the game, each subject had to allocate his endowment between a private account and a collective account. The investment in the private account corresponds to the private consumption and the investment in the collective account to the voluntary contribution to the public good.

In order to avoid difficulties due to the multiplicity of equilibria as in Chan et al. (1996), we rely on a quadratic payoff function which has two nice advantages: first, it implies a unique dominant strategy equilibrium, as in Keser (1996) and second, for a suitable choice 
of parameters it provides integer solutions in contrast to Chan et al. (1996), which fit to our experimental needs. Under suitable restrictions only interior solutions exist for a wide range of incomes. Therefore the solutions are clearly independent from income, which establishes directly Warr's result. We have:

$$
u_{i}\left(x_{i}, g\right)=41 x_{i}-x_{i}^{2}+15 g
$$

with $w_{i}=x_{i}+g_{i}$ is player $i$ 's endowment, $x_{i}$ his investment in the private account and $g_{i}=w_{i}-x_{i}$ his investment in the collective account with $g=\sum_{i=1}^{n} g_{i}$. It is easy to see that player $i$ 's optimal investment in the private account is independent of his income, since: $\frac{\partial U_{i}}{\partial x_{i}}=0 \Leftrightarrow 41-2 x_{i}-15=0 \Leftrightarrow x_{i}^{*}=13, \forall i$ and $\forall w_{i} \geq 13 .{ }^{5}$

With our specifications the "residual" contributions to the public good are equal to $g_{i}^{*}=$ $w_{i}-13, \forall i$. Therefore, if $w_{i}>13$ is satisfied for all players before and after redistribution, each player will invest a strictly positive amount in the public account. Conversely, the individual equilibrium contribution to the public account, $g_{i}$, depends only on endowment. In our design, the possible endowments of subjects are 15, 20 or 25 tokens. Therefore the unique interior Nash equilibrium is a dominant strategy equilibrium with $g_{i}^{*}=2$ if $w_{i}=15, g_{i}^{*}=7$ if $w_{i}=20$ and $g_{i}^{*}=12$ if $w_{i}=25$. In terms of final payoffs, there is theoretically no payoff difference between rich and poor players: at equilibrium the poor contribute less than the rich after having chosen their level of private consumption, while the public good is equally distributed among group members. Similarly, at the optimum level of public good provision-which is reached whenever each group member contributes his endowment-payoffs are also equalized within the group. We therefore conjecture that the inequality aversion model cannot account for the observed departures either from equilibrium play nor from the optimum. We shall discuss this conjecture in section 6 .

\footnotetext{
${ }^{5}$ The constituent game is based on the above payoff function, although players were not given this formula in the instructions. Instead, each subject received a payoff table indicating his marginal payoff for each token invested in the private account as well as the total payoff as a function of the number of tokens invested in the private account. They were aware that any token invested in the public account gave a payoff of 15 points for the investor as well as for each other member of the group. Payoff tables are available in the instructions given in the online appendix.
} 


\subsection{Practical procedures}

We conducted the experiment in a computerized laboratory at the Université de Montpellier 1, with the software z-Tree (Fischbacher, 2007). We ran seven sessions involving 16 subjects and two sessions involving eight subjects. The 128 subjects were randomly selected from a pool of student-subjects containing more than 1,000 volunteers from the Universities of Montpellier. Upon arriving at the experimental lab, subjects were randomly assigned to groups of four persons which remained fixed for the whole session. The experiment consisted of 20 periods of play of the constituent game. Written instructions ${ }^{6}$ were provided at the beginning of the experiment only for the first 10 periods. After period 10 a second set of instructions was distributed for the remaining 10 periods. In each period subjects were asked to invest each of their tokens in a private account or in a public account. At the end of each period the following information was displayed on each subject's computer screen: the amount he invested in each of the two accounts, the total contribution to the public account by the group, his earning from the private account, his earning from the public account and his total earnings for the current period. Furthermore, the record of previous periods was always reminded on the screen.

To allow for a direct test of redistribution in the spirit of Warr (1983) as discussed in section 3, we chose a within-subject design in which each subject faced two income distributions. This was done by letting each group play two sequences of 10 periods. After an initial 10-period sequence, income was redistributed (or not, for benchmark treatments) within groups and a second sequence of 10 periods was played out. This setting allows us to study the effect of income redistribution within each group, and to identify the adjustments of subjects who become poorer or richer. At the beginning of the experiment, subjects were unaware that they would play a second sequence of 10 periods within the same group. At the end of the 10th period, a new sequence of 10 periods was publicly announced. Subjects were given a new set of instructions, which emphasized the eventual changes with respect to the first sequence, namely the new income distribution among the group members. Each independent group was endowed with 80 tokens. The 80 tokens were split between the four

\footnotetext{
${ }^{6}$ The instructions of our experiment follow closely Keser (1996) and Willinger and Ziegelmeyer (2001), except that we added a second sequence in the experiment. Instructions are included in the online appendix.
} 
subjects either in an egalitarian way (20 tokens per subject) or in a non egalitarian way (two subjects received 15 tokens and two subjects received 25 tokens).

We chose not to announce the redistribution at the beginning of the experiment in order to avoid uncontrolled effects that could have been generated by differing expectations across subjects about their future endowment after redistribution. Subjects could have been more or less optimistic/pessimistic about their future endowment which would have affected their contribution to the public good in the first sequence. But our procedure could have created a deceptive feeling for some subjects who believed that the experiment would end after 10 periods. This feeling is not very well known and probably mild, but as explained below our design compensates for such possible effect. A more serious worry with our design is the possibility of a "restart effect" because subjects discovered only at the end of sequence 1 that they would be playing a second sequence of 10 periods with the same participants. Such restart effect was observed earlier by Andreoni (1988), Isaac and Walker (1988) and Croson (1996) in linear public good games and might represent an important confounding factor for the study of the effects of redistribution on contributions. Indeed restarting a new sequence in

fixed groups after the last period of the announced initial sequence tends to increase sharply the contributions at the beginning of the new sequence. As explained in the next section we control for such effect.

Wealth effects represent another possible confounding factor for the redistribution effect: a subject who accumulated a large (small) amount of points in the first sequence could have been encouraged to make large (low) contributions in the second sequence even after discovering that his endowment has been lowered (increased). We controlled for such eventual wealth effects by announcing to subjects that only one of the two sequences will be paid. At the end of the experiment one of the two sequences was randomly chosen and for each subject was paid according to his accumulated number of points that were converted into cash.

\subsection{Treatments}

To test the neutrality theorem, we implemented four treatments involving two sequences of 10 repetitions of the constituent game: two benchmark treatments (without redistribution) 
and two test treatments (with redistribution). We collected eight independent units of observation per period for each treatment (eight groups of four subjects per treatment). The two benchmark treatments are introduced to isolate the restart effect: one for the equal endowment distribution and one for the unequal endowment distribution. For the two test treatments a redistribution of the group token endowment was implemented after the first sequence. We consider two kinds of redistribution: unequalizing and equalizing. In the unequalizing redistribution, subjects belonging to a given group have the same endowment in the initial sequence and face an unequal distribution in the second sequence. In contrast in the equalizing treatment they start with an unequal distribution in the first sequence and move to an egalitarian distribution of endowments in the second sequence. The comparison of these two treatments will allow us to identify possible effects due to the type of redistribution: equalizing or unequalizing.

The benchmark treatments were designed to wipe out the so-called "restart effect" (Andreoni, 1988; Isaac and Walker, 1988; Croson, 1996) that corresponds usually to a sharp increase in contribution at the beginning of a new and unexpected restart of the game. To control for this effect, we compare the second sequence of each benchmark treatment (without redistribution) to the second sequence of the corresponding test treatment (with redistribution). Without confusion the benchmark treatments are labelled Equal-Equal (EE) and Unequal-Unequal (UU) while the test treatments are labelled Equal-Unequal (EU) and Unequal-Equal (UE), in the order of the sequences. The distribution of tokens was common knowledge. The experimental design is summarized in table 1. 


\begin{tabular}{|c|c|c|c|c|}
\cline { 2 - 5 } \multicolumn{1}{c|}{} & \multicolumn{2}{c|}{ Benchmark treatments } & \multicolumn{2}{c|}{ Test treatments } \\
\cline { 2 - 5 } & EE treatment & UU treatment & EU treatment & UE treatment \\
\hline $\begin{array}{c}\text { Endowments } \\
\text { before } \\
\text { redistribution }\end{array}$ & $80=(20,20,20,20)$ & $80=(15,15,25,25)$ & $80=(20,20,20,20)$ & $80=(15,15,25,25)$ \\
\hline $\begin{array}{c}\text { Nash- } \\
\text { contribution }\end{array}$ & $28=(7,7,7,7)$ & $28=(2,2,12,12)$ & $28=(7,7,7,7)$ & $28=(2,2,12,12)$ \\
\hline $\begin{array}{c}\text { Redistribution is } \\
\text { Endowments } \\
\text { after } \\
\text { redistribution }\end{array}$ & $80=(20,20,20,20)$ & $80=(15,15,25,25)$ & $80=(15,15,25,25)$ & $80=(20,20,20,20)$ \\
\hline $\begin{array}{c}\text { Non existent } \\
\text { contribution }\end{array}$ & $28=(7,7,7,7)$ & $28=(2,2,12,12)$ & $28=(2,2,12,12)$ & Equalizing \\
\hline
\end{tabular}




\section{Results}

The results section is organized as follows. Subsection 5.1 summarizes some preliminary results that show that our data are "well-behaved" and consistent with previous findings in public goods experiments (the complete tests are available in the online appendix). Subsection 5.2 states our main results about the neutrality of redistribution based on across and within tests at group level. Subsection 5.3 analyzes individual adjustments to redistribution.

We run two types of analyzes: non-parametric tests and OLS regressions on panel data with control for dependencies between decisions within groups (clusters). Unless otherwise specified, all of our tests are two-sided at the 5 percent significance level.

\subsection{Preliminary results}

Before we analyze the impact of redistribution on individual contributions, it is useful to check whether our data are homogeneous and satisfy well-established regularities commonly observed in experiments on voluntary contributions to public good.

A first insight of our data is given in figures 1 and 2 for test treatments and in figures 3 and 4 for benchmark treatments. These figures describe the average contributions according to subjects' endowments. They show a classical pattern in public good experiments with a dominant strategy interior equilibrium: a moderate over-contribution and a slight decline of the average contribution over periods. It can also be observed that the restart of the game just

after the 10th period does not radically affect the pattern of contributions for benchmark treatments. The same observation can be made for test treatments after redistribution. Finally, it seems that the poor and the rich do not contribute in a similar way. 
Figure 1: Average contributions: EU treatment

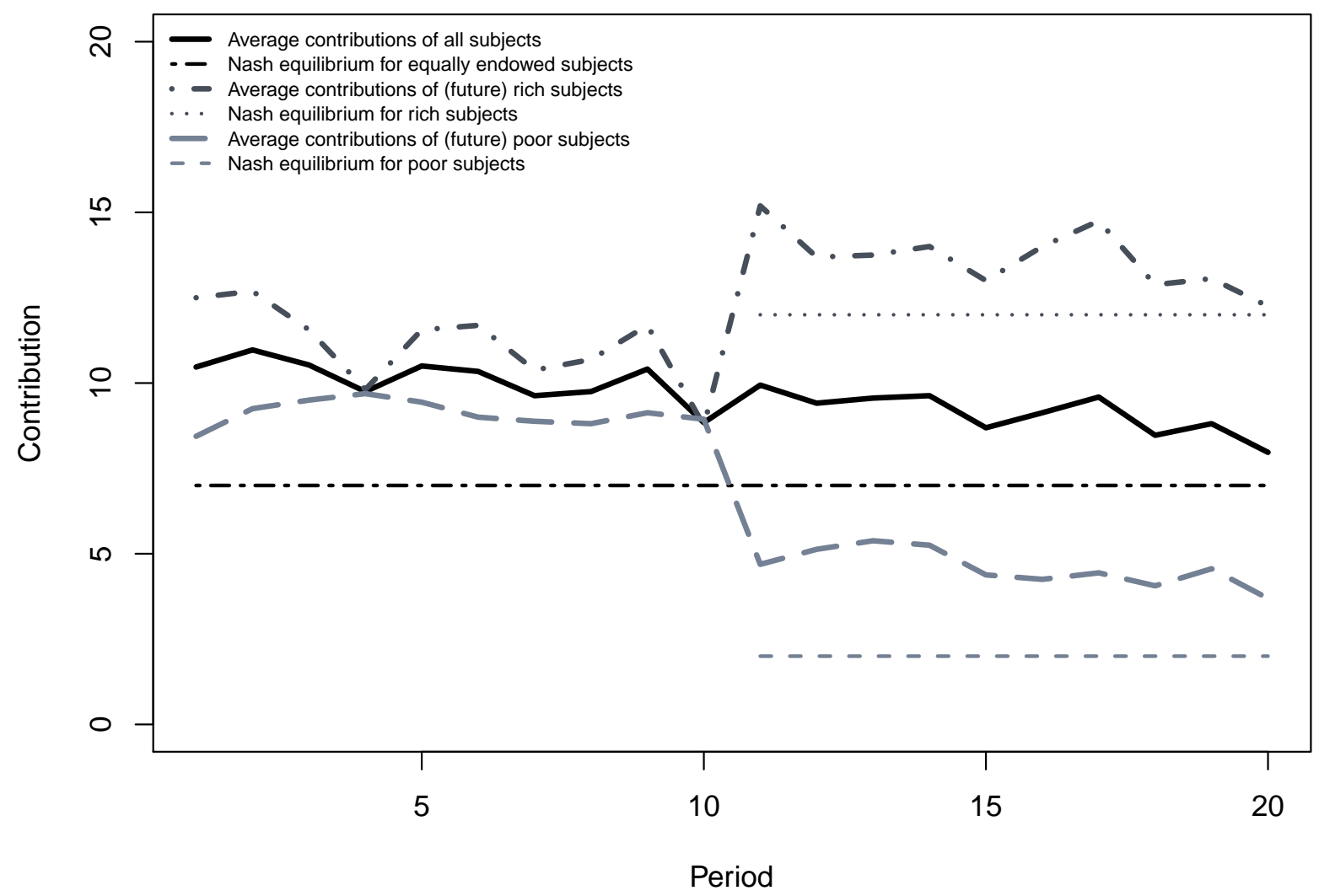


Figure 2: Average contributions: UE treatment

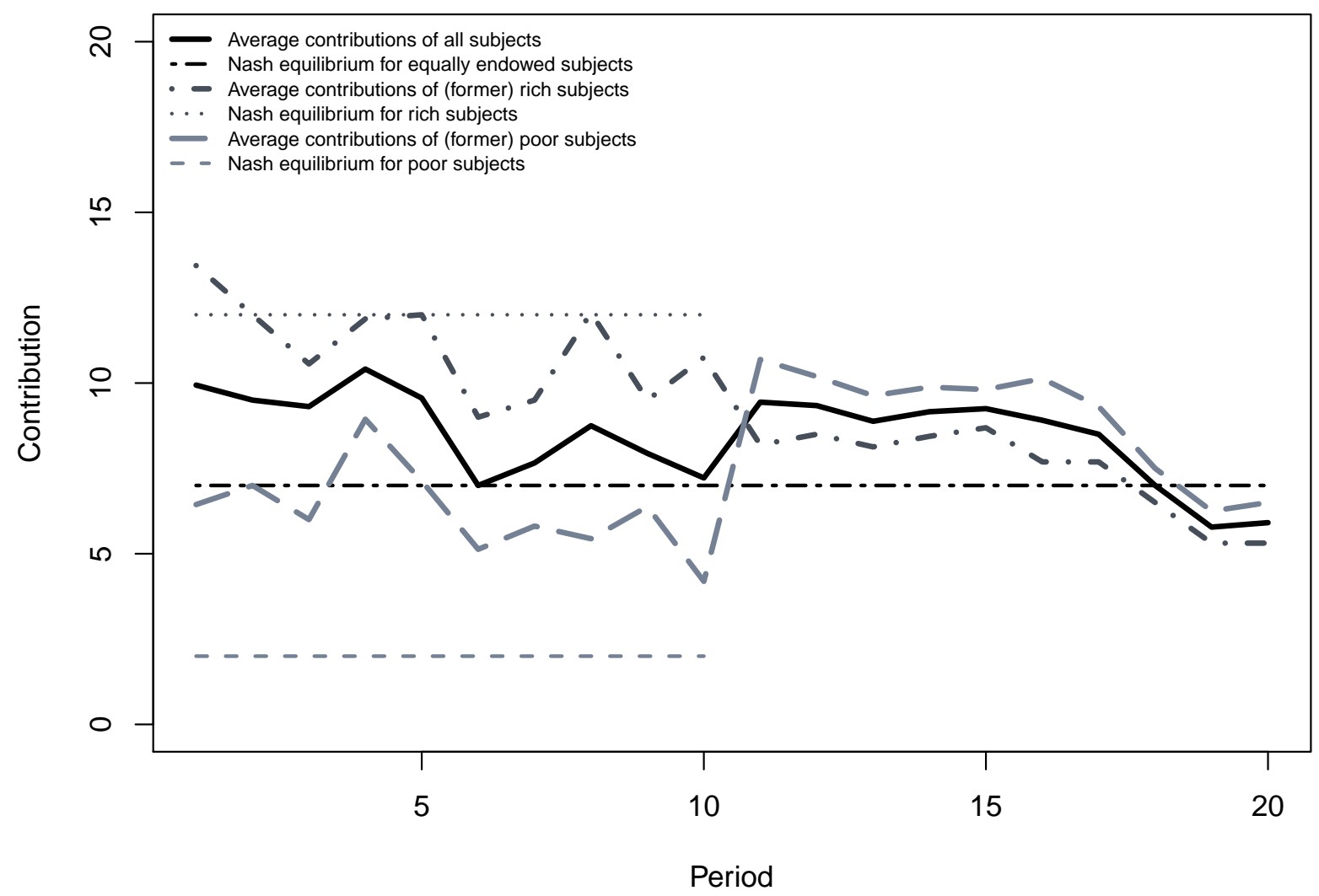


Figure 3: Average contributions: EE treatment

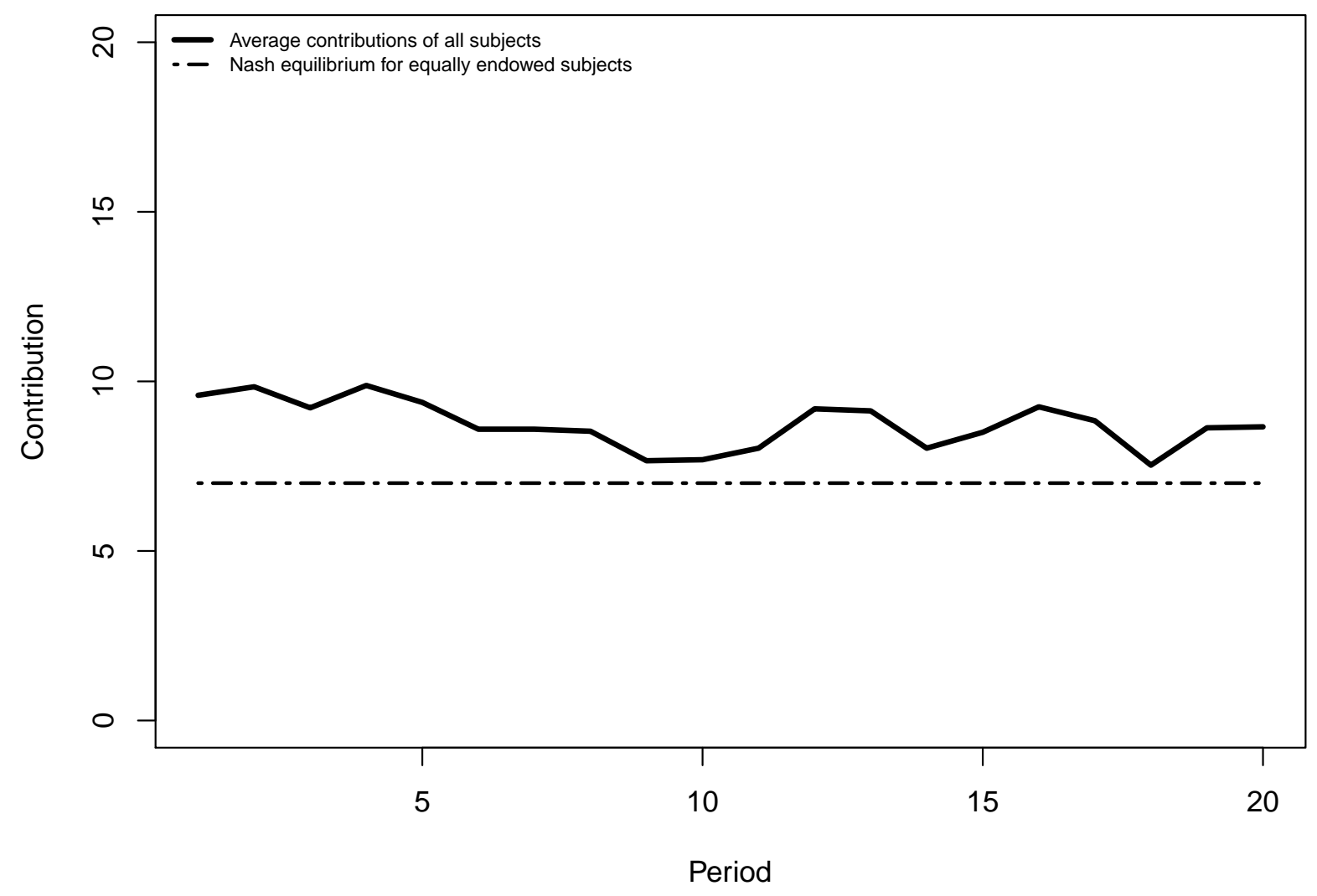


Figure 4: Average contributions: UU treatment

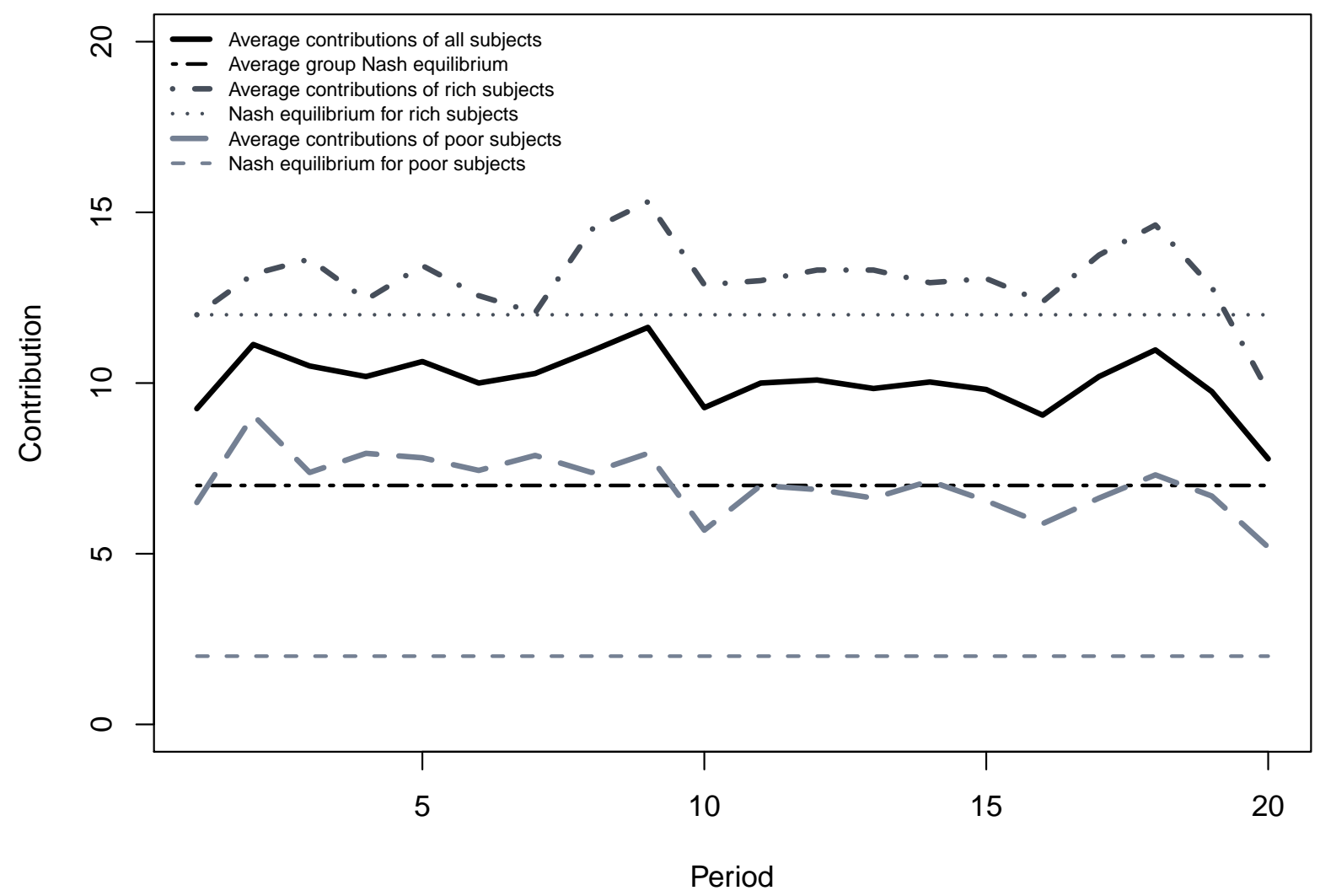

We run statistical tests to confirm these first observations and to guarantee that our main results are not the outcome of some uncontrolled particularities of our data set (see also part A of the online appendix). First we control for the homogeneity of the sequence 1 data across treatments, i.e. we control that subjects of each treatment behave the same way when they are in the same experimental conditions for the first sequence (namely EE vs. EU first sequences and UU vs. UE first sequences). We find that groups of subjects who face the same endowment distribution contribute on average the same amount to the public good. Secondly, we find that the ordering of the sequences does not affect the level of contributions. Third we control for over-contribution and decay of contributions over periods. Over-contribution is observed in all sequences of all treatments, but it is not always significant. The decay 
of contributions is not significant but always observed in our data: OLS regressions report always negative coefficients related to the variable accounting for the period, even if they are never significant at the 5 percent level. Both results are common observations of public good experiments with interior equilibrium. Finally we test for the presence of a potential restart effect between periods 10 and 11. Our tests do not detect any significant restart effect in our two benchmark treatments (EE and UU). We conclude from our preliminary analysis that any remaining effect detected in the data after redistribution is attributable to redistribution as such, and neither to restart, ordering of sequences or idiosyncratic heterogeneity.

\section{$5.2 \quad$ Neutrality at group level}

The main finding is that our experimental data are consistent with Warr's neutrality prediction, both between groups (result 1) and within groups (result 2).

Result 1. After redistribution groups with an unequal income distribution contribute the same amount as groups with an equal income distribution.

Support for result 1. We compare average group contributions in second sequences across treatments having the same first sequence, i.e. EE with EU and UU with UE. The null hypothesis of no difference in contribution between the average group contributions cannot be rejected (second sequence of EE vs. second sequence of EU: p-value $=0.505$ and second sequence of UU vs. second sequence of UE: p-value = 0.270; Mann-Whitney-Wilcoxon test).

We conclude from result 1 that the between test is consistent with the neutrality prediction. We now check whether this result also holds for within group comparisons. Since we did not find evidence of a restart effect in our benchmark treatments, we tentatively assume that it is also absent in our test treatments when we perform the within-subject comparisons.

Result 2. The average contribution of sequence 1 is equal to the average contribution of sequence 2 in each treatment. 
Support for result 2. We compare the average group contribution of the first sequence to the average group contribution of the second sequence for each group. The null hypothesis cannot be rejected neither for the test treatments (p-value $[\mathrm{EU}]=0.195^{7}$ and $\mathrm{p}$-value $[\mathrm{UE}]=0.383$; Wilcoxon signed-rank test) nor for the benchmark treatments (p-value[EE] $=0.640$ and $\mathrm{p}$-value $[\mathrm{UU}]=0.383)$. We conclude at this stage that our within-subject analysis is consistent with the results of between tests, and supports Warr's prediction that income redistribution does not affect the amount contributed by the group to the public good.

To complement the non-parametric tests we run OLS regressions by taking the group contribution as the dependent variable. The explanatory variables are "previous group contribution" and a "redistribution dummy" which takes value 0 for periods $1-10$ and value 1 for periods 11-20. We find that the variable "redistribution" is never significant (see table 2).

Table 2: Redistribution effect (OLS regressions on group contributions - clusters on groups)

\begin{tabular}{clllll}
\hline & & EE & UU & EU & UE \\
\hline \hline $\begin{array}{c}\text { Previous } \\
\text { group }\end{array}$ & Coefficient & $0.657^{* * *}$ & $0.697^{* * *}$ & $0.912^{* * *}$ & $0.842^{* * *}$ \\
contribution & p-value & 0.003 & 0.000 & 0.000 & 0.000 \\
\hline \multirow{2}{*}{ Redistribution Std. Err. } & 0.149 & 0.048 & 0.082 & 0.032 \\
& Coefficient & 0.022 & -1.644 & -0.510 & -0.629 \\
& Robust Std. Err. & 1.000 & 1.065 & 0.689 & 0.741 \\
& p-value & 0.983 & 0.167 & 0.483 & 0.425 \\
\hline
\end{tabular}

Constants coefficient and p-value are not reported in the table.

Comments on results 1 and 2. Our results confirm the findings of Chan et al. (1996): the average contribution of groups with unequal income distribution does not differ from

\footnotetext{
${ }^{7}$ At the request of an anonymous referee we run additional EU sessions. The additional data of 5 more EU groups do not affect results 1 and 2; rather they increase the p-values from 0.505 to 0.860 for result 1 and from 0.195 to 0.263 for result 2 .
} 
the average contribution of groups with equal income distribution. In addition to Chan et al. (1996), our design allows us to test the neutrality theorem of Warr thanks to the implementation of an effective redistribution of income within groups. Our results also confirm the prediction that, if the set of contributors is invariant before and after redistribution, an equalizing or unequalizing redistribution is neutral for the provision of a unique public good. Thus we corroborate the neutrality result of Warr (1983) at the collective level.

\subsection{Individual adjustments to redistribution}

According to Warr's predictions, after a redistribution of income, agents adjust their contribution by an amount that is equal to their income variation, i.e. adjustments of the "poor" and the "rich" cancel out, leaving the aggregate contribution unchanged.

In order to study individual behavior, we first run OLS regressions on individual contribution and over-contribution (which is defined as subject $i$ 's actual contribution - subject $i$ 's predicted Nash contribution, see section 5.3.2 for more details on over-contribution). Explanatory variables are the contribution of the group at the previous period ("previous group contribution" variable) and a dummy for the endowment of subject $i$ (there are three possible endowments: 15, 20 or 25; the reference is 20 except for UU where the reference is 15). As can be seen from table 3, subjects adjust their contribution according to their endowment: the endowment dummy is always significant for both test treatments. They contribute less when they are poorer and more when they are richer as shown by the sign of the endowment dummies coefficients. 
Table 3: Individual behaviors in treatments with inequality (OLS regressions on individual contributions - clusters on groups)

\begin{tabular}{|c|c|c|c|c|c|}
\hline & & & EU & UE & UU \\
\hline \multirow{9}{*}{ 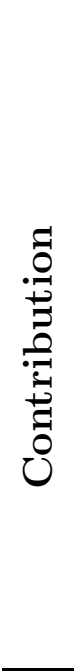 } & Previous & Coefficient & $0.228 * * *$ & $0.211^{* * *}$ & $0.175 * * *$ \\
\hline & group & Robust Std. Err. & 0.021 & 0.008 & 0.012 \\
\hline & contribution & p-value & 0.000 & 0.000 & 0.000 \\
\hline & & Coefficient & $-4.586 * * *$ & $-2.145 * * *$ & \\
\hline & Endowment $=15$ & Robust Std. Err. & 0.370 & 0.598 & ref. \\
\hline & & p-value & 0.000 & 0.009 & \\
\hline & & Coefficient & $4.331 * * *$ & $2.459 * * *$ & $6.108 * * *$ \\
\hline & Endowment $=25$ & Robust Std. Err. & 0.208 & 0.584 & 1.408 \\
\hline & & p-value & 0.000 & 0.004 & 0.003 \\
\hline \multirow{9}{*}{ 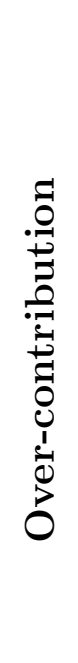 } & Previous & Coefficient & $0.228 * * *$ & $0.211^{* * *}$ & $0.175^{* * *}$ \\
\hline & group & Robust Std. Err. & 0.021 & 0.008 & 0.012 \\
\hline & contribution & p-value & 0.000 & 0.000 & 0.000 \\
\hline & & Coefficient & 0.414 & $2.856^{* * *}$ & \\
\hline & Endowment $=15$ & Robust Std. Err. & 0.370 & 0.598 & ref. \\
\hline & & p-value & 0.300 & 0.002 & \\
\hline & \multirow{3}{*}{ Endowment $=25$} & Coefficient & $-0.669 * *$ & $-2.541 * * *$ & $-3.892 * *$ \\
\hline & & Robust Std. Err. & 0.208 & 0.584 & 1.408 \\
\hline & & p-value & 0.015 & 0.003 & 0.028 \\
\hline
\end{tabular}

Constants coefficient and p-value are not reported in the table; we run the same regressions with the "period" variable as another explaining variable but it does not change the results.

\subsubsection{Under-adjustment and asymmetry}

In this subsection we further investigate individual reactions to redistribution by analyzing the magnitude of subjects' adjustments. We define a subject's individual adjustment as the difference between his average contribution before and after redistribution, for treatments 
EU and UE. We then compare subjects' individual adjustments to the predicted adjustment in Warr's model, i.e. equality with income variation.

It is an open question whether after a redistribution of the group endowment subjects adjust their contribution as predicted. The overwhelming experimental evidence about voluntary contributions is that subjects over-contribute with respect to their Nash contribution level. Furthermore there is mixed evidence about the effect of endowment heterogeneity on the average level of over-contribution (see Zelmer, 2003; Cherry et al., 2005; Buckley and Croson, 2006; Hofmeyr et al., 2008). It is nevertheless fair to say that subjects tend to over-contribute under various endowment distributions. Given the parametric setting of our experiment the predicted Nash-adjustments are $+/-5$ tokens $(+5$ for agents who become richer and -5 for agents who become poorer). Our data reveals that most subjects do adjust their contribution in the predicted direction, but with a lower magnitude than expected. We also observe that subjects who get poorer tend to adjust by a larger absolute amount than the subjects who get richer. This observation opens an interesting avenue for future experimental research. Let us first state result 3:

Result 3. (3a) Subjects tend to under-adjust, both with respect to an equalizing and an unequalizing redistribution.

(3b) The magnitude of the adjustment is larger for subjects who become poorer after redistribution, but adjustment asymmetry between the poor and the rich fails to be significant.

Support for result 3. Table 4 summarizes the average adjustments of poor and rich subjects for the test treatments. The table clearly shows that on average the magnitude of the adjustment is lower than 5 in all treatments and for all endowment levels. It is also apparent that the average adjustment is larger for subjects who get poorer compared to those who get richer. 
Table 4: Average adjustments to redistribution and tests for under-adjustment (binomial tests)

\begin{tabular}{|r|c|c|c|c|}
\hline \multirow{2}{*}{ Treatment: } & \multicolumn{2}{|c|}{ EU } & \multicolumn{2}{c|}{ UE } \\
\cline { 2 - 5 } & $\begin{array}{c}\text { Average } \\
\text { adjustment }\end{array}$ & $\begin{array}{c}\text { Under- } \\
\text { adjustment }^{a}\end{array}$ & $\begin{array}{c}\text { Average } \\
\text { adjustment }\end{array}$ & $\begin{array}{c}\text { Under- } \\
\text { adjustment }\end{array}$ \\
\hline Subjects becoming richer $^{b}$ & +2.53 & Yes & +2.68 & Yes \\
\hline Subjects becoming poorer $^{c}$ & -4.53 & No & -3.71 & Yes \\
\hline
\end{tabular}

${ }^{a}$ We run binomial tests with the following null hypothesis: average group adjustments by type of subjects are equal to their related variation of income (Nash-adjustment).

${ }^{b}$ Rich subjects in EU and poor subjects in UE.

${ }^{c}$ Poor subjects in EU and rich subjects in UE.

We rely on the average contribution of the two poor (rich) subjects for each group in order to run non-parametric tests at the group level. Subjects who become richer increase their contribution on average by 2.53 tokens in the EU treatment and by 2.68 tokens in the UE treatment. Both adjustments are significantly less than 5 (binomial test: p-value $=0.035$ for $\mathrm{EU}$; p-value $=0.035$ for $\mathrm{UE}$ ). Subjects who become poorer lower their contribution on average by 4.53 tokens in the EU treatment and by 3.71 tokens in the UE treatment. Only the latter value is significantly lower than 5 (binomial test: $\mathrm{p}$-value $=0.035$ ) while in the EU case the poor adjust as predicted, i.e. they reduced by 5 tokens their contribution level (binomial test: $\mathrm{p}$-value $=0.363){ }^{8}$

We test for adjustment asymmetry by comparing the adjustment difference between rich and poor subjects. The null hypothesis is that the adjustment difference between rich and poor subjects is equal to zero. Adjustment-asymmetry between the rich and the poor is visible in each of the test treatments, and even more pronounced in the case of an unequalizing redistribution. However, none of the tests reveals a significant adjustment difference between the rich and the poor (one-sided Mann-Whitney-Wilcoxon test: p-value[EU] $=0.104$;

\footnotetext{
${ }^{8}$ Section C.2 of the online appendix, tables 7 and 8, summarizes the average contribution per subject for the EU and UE treatments and shows each subject's average over- or under-adjustment after redistribution (with respect to the Nash-adjustment).
} 
p-value $[\mathrm{UE}]=0.191)$.

Comment. Despite the fact that the magnitude of the adjustments to redistribution of rich and poor subjects are lower than predicted, result 3 does not contradict our findings about neutrality (results 1 and 2). Nevertheless, the observation of an asymmetric adjustments between the rich and the poor is puzzling. Potentially such asymmetry could have challenged the predictions of Warr's theorem, especially in the unequalizing treatment. However, with our specific setting (two rich and two poor subjects) the asymmetry of adjustments between rich and poor subjects is not strong enough to undermine neutrality: even though the adjustments of the rich and the poor do not perfectly cancel out in the EU treatment (in contrast to the UE treatment) group contributions are nevertheless more or less equal before and after redistribution so that neutrality still holds.

Why asymmetric adjustments between the rich and the poor is more pronounced after an unequalizing redistribution remains an open question. A plausible explanation relies on the perception of the redistribution in terms of fairness, especially for subjects who become poorer. A given loss of income may be more acceptable when moving towards a more egalitarian society (i.e. moving from "upper class" to "middle class") than when moving towards a less egalitarian society (i.e. moving from "middle class" to "lower class"). After an unequalizing redistribution poor subjects might have felt stronger unfairness with respect to their income-change than former rich subjects after the equalizing redistribution. Again, we believe that with our setting (two rich and two poor subjects) the asymmetry effect is not strong enough to ruin neutrality. However, for larger populations with fewer rich than poor subjects such asymmetry could strongly affect the level of group contribution, and contradict neutrality.

To summarize, after redistribution both the subjects who become richer and those who become poorer under-adjust with respect to the Nash-adjustment. Asymmetric adjustment is more pronounced after an unequalizing redistribution: subjects who become richer increase their contribution by a lower amount than subjects who become poorer reduce their contribution, although the adjustment difference is not significant. 


\subsubsection{Over-contribution differences}

To test for over-contribution differences between subjects, we compute the average contribution of the two poor and the two rich subjects separately for each group and compare each of them to its Nash-prediction: two tokens for poor subjects and 12 tokens for rich subjects. We summarize our findings as result 4 .

Result 4. Poor subjects significantly over-contribute while rich subjects Nash-contribute.

Support for result 4. Table 5 provides detailed test-results on the over-contribution of poor and rich subjects. We run binomial tests separately for each non egalitarian sequence. The binomial test concludes about significance of over-contribution if seven or more groups over-contribute on average in the studied sequence. The test results are reported in table 5. The poor significantly over-contribute whereas the rich do not. 
Table 5: Over-contribution by subjects' type (binomial tests)

\begin{tabular}{|c|c|c|c|c|c|c|}
\hline Treatment & Periods & Types & $\begin{array}{c}\text { Average } \\
\text { Contribu- } \\
\text { tion }\end{array}$ & Freq. $^{a}$ & p-value & $\begin{array}{l}\text { Over- } \\
\text { contri- } \\
\text { bution }\end{array}$ \\
\hline \multirow{2}{*}{ EU } & \multirow{2}{*}{11 to 20} & Poor & 4.58 & 7 & 0.035 & Yes \\
\hline & & Rich & 13.66 & 5 & 0.363 & No \\
\hline \multirow{4}{*}{$\mathbf{U E}^{b}$} & \multirow{2}{*}{1 to 10} & Poor & 6.31 & 7 & 0.035 & Yes \\
\hline & & Rich & 11.15 & 5 & 0.363 & No \\
\hline & \multirow{2}{*}{11 to 20} & Former poor & 8.99 & 7 & 0.035 & Yes \\
\hline & & Former rich & 7.44 & 4 & 0.633 & No \\
\hline \multirow{4}{*}{ UU } & \multirow{2}{*}{1 to 10} & Poor & 7.50 & 8 & 0.004 & Yes \\
\hline & & Rich & 13.26 & 5 & 0.363 & No \\
\hline & \multirow{2}{*}{11 to 20} & Poor & 6.56 & 8 & 0.004 & Yes \\
\hline & & Rich & 12.94 & 4 & 0.633 & No \\
\hline
\end{tabular}

${ }^{a}$ The column reports the number of groups of poor/rich subjects among the 8 groups of the experiment having an average group contribution above their equilibrium for the corresponding periods.

The Nash equilibrium of a poor subject is 2 tokens.

The Nash equilibrium of a rich subject is 12 tokens.

${ }^{b}$ We also study the second sequence of this treatment (periods 11 to 20) to distinguish the behavior of the former poor subjects and of the former rich subjects.

The Nash equilibrium of each subject is 7 for periods 11 to 20 in this treatment.

We also run OLS regressions similar to those for result 3 but with individual overcontribution as the dependent variable. The results are reported in the second part of table 3 and confirm the results of the binomial tests: subjects over-contribute significantly less when they become richer. Over-contribution of the poor is not affected by redistribution in the EU treatment and becomes larger in the equality sequence of the UE treatment. Finally in the UU treatment, rich subjects over-contribute significantly less than poor subjects.

Figures 1, 2 and 4 show the average contributions of poor and rich subjects with respect to 
their Nash-contribution. Moreover, for the second sequence of treatment UE we distinguish the average contribution of the former poor subjects to the average contribution of the former rich subjects to detect eventual changes in over-contribution rates. These behaviors are stated as result 5. We also add the average contribution of the future poor and future rich subjects in the first sequence of treatment EU to exhibit their behavior before the unequalizing redistribution.

Result 5. After an equalizing income redistribution, former poor subjects continue to over-contribute and former rich subjects continue to Nashcontribute.

Support for result 5. Table 5 shows that in seven groups out of eight the former poor subjects over-contribute on average in the second sequence of UE whereas only in four groups out of eight do the former rich subjects over-contribute. Therefore binomial tests support result 5 .

Comments on results 4 and 5 . Table 5 shows a remarkable difference in contribution behavior between rich and poor subjects. Although on average both types of subjects overcontribute with respect to their Nash-contribution, over-contribution is significant only for poor subjects. As can be seen from table 5 in every sequence with unequal distribution ${ }^{9}$, one observes that rich subjects do not contribute significantly more than their Nash-contribution while poor subjects always over-contribute on average. We conclude therefore that this overcontribution asymmetry between rich and poor is not generated by the redistribution of income as such, but merely by the existence of an unequal distribution at the outset of a sequence, a result which is in accordance with the earlier findings by Chan et al. (1996).

\section{Discussion}

According to our data redistribution of income is neutral at group level: a redistribution of the aggregate income among group members does not affect the aggregate group contribution.

\footnotetext{
${ }^{9}$ In sequence 1 of treatment UE, sequence 2 of treatment EU and sequences 1 and 2 of treatment UU.
} 
Furthermore, at individual level, subjects adjust their contributions in the predicted direction: those who become richer increase their contribution and those who become poorer reduce their contribution.

However, following an unequalizing redistribution subjects who become poorer tend to over-contribute while subjects who become richer tend to Nash-contribute. The disparity in over-contribution between the rich and the poor cannot be attributed to redistribution as such, since we observe the same contribution disparity without redistribution, in first sequences with unequal endowments. What are the possible reasons for such asymmetry in contributions between rich and poor subjects? Clearly, subjects do not react as standard selfish-utility maximizers. We therefore explore alternative hypotheses about their preferences that might account for the observed asymmetry. In the following discussion, we concentrate on two plausible explanations that may account for our main findings: inequality aversion (Fehr and Schmidt, 1999), and the relative "strength of the social dilemma" (Willinger and Ziegelmeyer, 2001) which is akin to Andreoni (1990)'s theory of impure altruism (or warm glow). We show that the latter explanation fits best to our findings. Besides, we have also explored other possibilities, in particular Quantal Response ${ }^{10}$ and behavioral explanations taken from the psychological literature about adjustment heuristics (e.g. regression towards the mean and extremeness aversion). However, we believe that explanations based on preferences provide a better way to organize our data.

Theories based on social preferences offer an alternative to the standard selfish preferences hypothesis that might account for our results. We first discuss why inequality aversion is not satisfactory for accounting for our results. Then we show how the "Relative Strength of the

\footnotetext{
${ }^{10}$ Are our data consistent with QRE? Anderson et al. (1998) showed that in the quadratic payoff case, QRE predicts that average contributions are sandwiched between the dominant strategy Nash equilibrium and half the endowment: this corresponds to the interval $[7,10]$ for an endowment of 20 tokens, $[12,12.5]$ for 25 tokens, and in $[2,7.5]$ for 15 tokens. We test whether group averages fall in these predicted intervals. The unit of observation is the average contribution of subjects with the same endowment within a group. The test is based on two different indicators: the average contribution of the last period in a sequence and the average contribution of the three last periods in a sequence. The binomial test ( 5 percent significance level) rejects the hypothesis that average contributions are located in the predicted range, for all endowment levels and all sequences.
} 
Social Dilemma" hypothesis (RSSD hereafter), which is formally equivalent to the warm glow model, predicts that the relative over-contribution decreases with the level of endowment as observed in our data.

\subsection{Inequality aversion}

Intuition suggests that inequality averse players should react, at least under some plausible assumptions, exactly like selfish players. Let us consider the easiest case: common knowledge of symmetric inequality-averse preferences. Starting from a situation of equal contributions (and therefore equal payoffs), redistribution implies that inequality-averse individuals who become richer should increase their contribution in order to compensate the lower income of individuals who become poorer, and symmetrically, the latter should lower their contribution to compensate for the larger income of individuals who become richer. Both types of adjustment should exactly cancel out to equalize final payoffs of both types. This is exactly the prediction of the standard hypothesis of selfish-utility maximizing agents. Starting from a situation where final payoffs are equalized, inequality-averse players adjust their contributions in order to prevent any final payoff inequality ${ }^{11}$. While inequality averse agents react in the same way as selfish-agents, their behavior with respect to an unequal income distribution as such might be different. However, even if no redistribution occurs, we expect that in a population of inequality-averse individuals, individuals over-contribute equally to avoid net payoff disparity. In this respect our findings remain puzzling, both with respect to selfishly oriented subjects and inequality-averse subjects.

\subsection{Relative strength of the social dilemma}

Willinger and Ziegelmeyer (2001) showed that the strength of the social dilemma, which corresponds to the gap between the Nash-contribution and the social optimum contribution,

\footnotetext{
${ }^{11}$ With our quadratic payoff function, there are many possible cases to consider for deriving predictions from the Fehr-Schmidt model. We studied a simplified version of this game, involving only 2 players. Our findings show that $(7,7)$ is always an equilibrium of the game with symmetric endowments, whatever the parameters $\alpha_{i}$ and $\beta_{i}$ of player $i=1,2$. Depending on the values of $\alpha_{i}$ and $\beta_{i}(i=1,2)$ we show that other symmetric equilibria may exist.
} 
drives subjects' contribution efforts. As the intensity of the social dilemma becomes stronger, subjects tend to make larger over-contributions. In other words, subjects behave as if they valued more their contribution to the public good when they are exposed to a stronger social dilemma, or alternatively as if the strength of the dilemma exerted a positive externality on their contribution.

Such tension may occur within individuals if they have conflicting preference orderings, for instance an inconsistency between their individual preferences and their preferences over group outcomes. The idea of multiplicity of preferences orderings within individuals goes back to Arrow (1951) who distinguished between tastes which correspond to the usual selfcentered preferences and values which take into account the society's interest, and Harsanyi (1955) who made the distinction between ethical values and the usual subjective preferences. Later on, Goodin (1986) proposed the idea of self-laundering preferences as a way to solve the individual's conflict in the case of a collective action: the "multiplicity of preference orderings matters because, in the context of collective decision-making, people will launder their own preferences. They will express only their public-oriented, ethical preferences, while suppressing their private-oriented, egoistic ones" (Goodin, 1986: 88). In the context of the social dilemma involved in the voluntary provision of a public good, the resolution of the individual's internal conflict cannot simply be externalized in a collective action because of the strategic dimension of the problem. We propose instead that each individual chooses a level of contribution that mitigates the tension involved in the social dilemma. We argue that such tension is stronger when individuals are poorer, leading therefore the poorest to contribute the largest fraction of their endowment.

In our experiment, the strength of the social dilemma - i.e. the absolute difference between the Nash-contribution and the socially optimum contribution-is independent with respect to income for the considered range of income variations: $(+5 ;-5)$. The difference is always equal to 13 tokens because both the individual optimum contribution and the individual Nash-contribution are shifted upwards or downwards by the same amount, leaving therefore the gap unaffected. However, if we measure the gap in relative terms, i.e. as a percentage of the endowment, the relative strength of the social dilemma is decreasing with the level of 
endowment ${ }^{12}$. Let us therefore define the RSSD as a function of income: $h(w)=\frac{w-g^{*}(w)}{w}$. Note that an agent's income $w$ is also his socially optimal level of contribution, while $g^{*}(w)$ is his Nash-contribution which increases with income. According to Warr $g^{*^{\prime}}(w)=1$ : a one euro increase of endowment increases the Nash-contribution by one euro. The numerator in $h(w)$ is therefore constant, which leads to:

Property. $h^{\prime}(w)<0$ and $h^{\prime \prime}(w)>0$.

Property 1 is a direct consequence of Warr's neutrality theorem. Our conjecture is that the RSSD affects positively an individual's over-contribution: an individual who is exposed to a stronger relative social dilemma tends to over-contribute a larger fraction of his endowment to the public good. Since the RSSD declines with endowment, we expect richer subjects to over-contribute less than poorer subjects. Define $R_{i}(w)=\frac{g_{i}(w)-g^{*}(w)}{w}$ as agent $i$ 's relative over-contribution. According to the RSSD hypothesis, $R_{i}^{\prime}(w)<0$. Our data are consistent with this prediction: on average we observe that $R_{i}(15)>R_{i}(20)>R_{i}(25)$. We give detailed test-results for each treatment and each income category in the online appendix (section B). Almost all tests are statistically significant. Since the RSSD hypothesis is compatible with our data, the relatively stronger social dilemma experienced by the poorer subjects might have increased their relative contribution efforts compared to the richer subjects who felt a weaker relative social dilemma.

In order to account for such effect on over-contributions, we develop a decision-theoretic model that formalizes the RSSD hypothesis. We state the following hypothesis: the actual contribution of an individual depends on his sensitiveness to RSSD. As the relative tension between his optimum contribution and his Nash-contribution increases, he feels a stronger incentive to contribute. Since the RSSD is stronger for poor agents than for rich agents, we expect the poor to contribute a larger fraction of their income than the rich.

We assume that player $i$ 's relative over-contribution $R_{i}(w)$ is a function of his RSSD. Let us define his utility as $u_{i}\left(x_{i}, g, g_{i}\right)$, where $g_{i}$ enters the utility function twice: first as a part of

\footnotetext{
${ }^{12}$ In Willinger and Ziegelmeyer (2001) the strength of the social dilemma was manipulated by changing the marginal return from the public good while keeping the endowment constant. Therefore, there was no point in distinguishing the absolute and relative strength of the social dilemma.
} 
the public good $(g)$ and second as a private good. This specification is formally equivalent to Andreoni (1990)'s theory of warm glow giving, but we provide a different interpretation why $g_{i}$ enters directly the utility function. Agent $i$ enjoys a positive reward from over-contributing because it alleviates the tension between his Nash-contribution and his optimum contribution.

Assuming separability, $u_{i}\left(x_{i}, g, g_{i}\right)$ can be rewritten as $u_{i}\left(x_{i}, g, g_{i}\right)=v_{i}\left(x_{i}\right)+\beta g+z_{i}\left(g_{i}\right)$. $v_{i}\left(x_{i}\right)$ captures the utility of the private consumption, $\beta g$ the utility of the public good and $z_{i}\left(g_{i}\right)$ the utility of the agent's own contribution for accommodating the relative strength of his social dilemma. We assume $v_{i}^{\prime}()>$.0 and $v_{i}^{\prime \prime}()<$.0 , i.e. the marginal utility of private consumption is positive and strictly decreasing. In our experiment $v_{i}\left(x_{i}\right)=41 x_{i}-x_{i}^{2}$ and $\beta=15$. The new part of the utility function is $z_{i}\left(g_{i}\right)$. We assume $z_{i}\left(g_{i}\right)=\alpha h(w) g_{i}$ where $\alpha \geq 0$ measures the agent's sensitivity to the social dilemma which, for simplicity, we assume to be identical to all agents. If either $\alpha=0$ or $h(w)=0$ the utility function degenerates to $u_{i}\left(x_{i}, g\right)$, and agent $i$ chooses his Nash-level of contribution $g_{i}(w)=w-v_{i}^{\prime-1}(\beta)=g^{*}(w)$ for which $R_{i}(w)=0$. If however both $\alpha \neq 0$ and $h(w) \neq 0$, agent $i$ chooses $x_{i}$ and $g_{i}$ to maximize $u_{i}\left(x_{i}, g, g_{i}\right)$, given that $x_{i}+g_{i}=w$ and $g=g_{i}+g_{-i}$. Substituting $w-g_{i}$ for $x_{i}$ and deriving with respect to $g_{i}$ gives the first-order condition for an interior solution:

$$
-v_{i}^{\prime}\left(w-g_{i}\right)+\beta+\alpha h(w)=0 .
$$

Solving for $g_{i}$ leads to the contribution function $g_{i}(w)=w-v_{i}^{\prime-1}(\beta+\alpha h(w))$ where $\beta+$ $\alpha h(w)$ may be interpreted as the agent's total valuation of his contribution to the public good. Since $v_{i}^{\prime}($.$) is decreasing we have g_{i}(w) \geq g^{*}(w)$ : if the agent is sensitive to the RSSD $(\alpha>0)$, his contribution is larger compared to his Nash-contribution, i.e. $R_{i}(w) \geq 0$.

We can now state the following:

Proposition. Given $h(w)$ and the above specification of $u_{i}\left(x_{i}, g, g_{i}\right)$, $R_{i}(w)$ is strictly decreasing with $w$.

Proof. $\quad R_{i}^{\prime}(w)=\frac{\left(g_{i}^{\prime}(w)-g^{*^{\prime}}(w)\right) w-\left(g_{i}(w)-g^{*}(w)\right)}{w^{2}}$. The second term of the denominator, $g_{i}(w)-g^{*}(w)$, is positive. The first term is positive if $g_{i}^{\prime}(w) \leq 1=g^{*^{\prime}}(w)$. Taking the derivative of $g_{i}(w)$, we have $g_{i}^{\prime}(w)=1-\alpha h^{\prime}(w) v_{i}^{\prime \prime}-1(\beta+\alpha h(w))$. Since $v_{i}^{\prime \prime-1}()<$.0 and $h^{\prime}(w)<0, g_{i}^{\prime}(w)<1$ and $R_{i}^{\prime}(w)<0$. 
With our experimental settings, $v_{i}\left(x_{i}\right)=41 x_{i}-x_{i}^{2}$ and $\beta=15$. We can therefore write $u_{i}\left(x_{i}, g, g_{i}\right)=41 x_{i}-x_{i}^{2}+15 g+\alpha h(w) g_{i}$. With this specification the contribution function is $g_{i}=w-13+\frac{\alpha h(w)}{2}$. One can easily show that $R_{i}(w)=\frac{\alpha h(w)}{2 w}$ and $R_{i}^{\prime}(w)<0$. Our data are consistent with this prediction since we observe that on average $R(15)>R(20)>R(25)$ in almost all sequences (see table 5 of the online appendix).

The above model can be adapted to account for over-contribution asymmetry in Chan et al.'s (1996) experiment ${ }^{13}$.

Since our model is formally equivalent to Andreoni's warm glow theory, it is important to underline that this model generally predicts non-neutrality. For instance, "if the income gainer is more altruistic [...] than the income loser," redistribution will increase the amount of voluntarily provided public good (Andreoni, 1990: 467, proposition 1). However, with our specification, neutrality almost holds because of the negligible impact of redistribution on the contribution function. Consider for instance the case of two identical agents (agents 1 and 2) with equal endowments $w$. The aggregate contribution to the public good is $2 g(w)=$ $2 w-26+\alpha h(w)=2 w-26+\alpha \frac{13}{w}$. After redistribution agent 2's endowment becomes $w_{2}=w+\mathrm{d} w$ and agent 1's $w_{1}=w-\mathrm{d} w$, such that $w_{1}<w<w_{2}$. The aggregate contribution to the public good is now equal to $g\left(w_{1}\right)+g\left(w_{2}\right)=w_{1}-13+\frac{\alpha h\left(w_{1}\right)}{2}+w_{2}-13+\frac{\alpha h\left(w_{2}\right)}{2}=$ $2 w-26+\frac{\alpha}{2}\left[h\left(w_{1}\right)+h\left(w_{2}\right)\right]=2 w-26+\alpha \frac{13 w}{w_{1} w_{2}}$. For a small redistribution $\frac{w}{w_{1} w_{2}} \approx \frac{1}{w}$ so that the group contribution is only marginally affected. For instance in our case where $w_{1}=15$ and $w_{2}=25, \frac{w}{w_{1} w_{2}}=\frac{20}{15 \times 25}=0.053333 \approx \frac{1}{20}=\frac{1}{w}$.

\section{Conclusion}

In this paper, we experimentally investigated the neutrality theorem of Warr (1983), according to which a redistribution of income among contributors to a public good has no effect on aggregate contributions. In order to test Warr's prediction, we designed a within-subject experiment based on a standard voluntary contribution game where a redistribution of the aggregate group income is implemented after 10 periods. The task of each subject was to

\footnotetext{
${ }^{13}$ Player $i$ 's utility can be written $u_{i}\left(x_{i}, g\right)=x_{i}+\beta g+\alpha h(w) g_{i}+g_{-i}+x_{i} g$. His best reply is to contribute $\max \left(0, \min \left(w, g_{i}^{\circ}\right)\right)$, where $g_{i}^{\circ}=\frac{w-g_{-i}+\alpha h(w)+\beta-1}{2}$, which is increasing with $h(w)$.
} 
allocate a fixed endowment between his private account and a group account. We relied on a quadratic payoff function for the private account in order to ensure that under standard behavioral assumptions there exists a unique interior dominant strategy equilibrium, for all income distributions considered in the experiment. We controlled for the restart effect that might have occurred after redistribution and which could be a possible confounding factor. Our data are consistent with the neutrality theorem at aggregate level: a redistribution of income among contributors has no significant impact on the aggregate contribution to the group good.

At individual level we find that poor subjects significantly over-contribute to the public good whereas rich subjects Nash-contribute. The redistribution of income does not affect this asymmetric contribution behavior. Furthermore we observe the same pattern in our unequal income distribution benchmark treatment where no redistribution was implemented. Consequently, only income inequality explains over-contribution differences between the rich and the poor. Finally, implementing a real redistribution of income within the experiment allows us to propose new insights with respect to individuals' reactions to inequalities. First, we observe that subjects adjust their contributions by a lower amount than the variation of their income (except for subjects who become poorer after an unequalizing redistribution). Second, after redistribution, we observe an asymmetric adjustment between poor and rich subjects, which however is not significant. The fact that this asymmetric adjustment seems to be more pronounced after an unequalizing redistribution raises the question of perceived fairness behind redistribution and could eventually challenge neutrality in a society with a greater proportion of poor people. This point opens an interesting agenda for future experimental research.

Since one of the most important fact in our data is asymmetric over-contribution, we offer a behavioral explanation of why poor subjects over-contribute more than the rich that is based on the strength of the social dilemma (Willinger and Zielgemeyer, 2001). We show that the "relative strength of the social dilemma" (RSSD) is stronger for the poor than for the rich subjects, leading to an over-contribution of the poor that is correspondingly larger than the over-contribution of the rich.

Our experiment is a first attempt to isolate the effects of income redistribution on group 
and individual contributions. We decided to focus on the particular outcome where redistribution is neutral, rather than on the more general prediction of BBV (1986), where redistribution can affect the set of contributors, and therefore neutrality does not necessarily hold. Of course, the latter case would be a natural extension of our research.

Jonathan MAURICE, Université Montpellier 1, MRM EA4557, F-34000 Montpellier, France

Agathe RouAIX, Université Montpellier 1, UMR5474 LAMETA, F-34000 Montpellier, France

Marc WiLlinger, Institut universitaire de France and Université Montpellier 1, UMR5474 LAMETA, F-34000 Montpellier, France

\section{References}

Anderson, S. P., J. K. Goeree, and C. A. Holt, "A Theoretical Analysis of Altruism and Decision Error in Public Goods Games," Journal of Public Economics 70 (1998), 297-323.

Andreoni, J., "Why Free Ride? Strategies and Learning in Public Goods Experiments," Journal of Public Economics 37 (1988), 291-304.

Andreoni, J. "Impure Altruism and Donations to Public Goods: A Theory of Warm-Glow Giving," The Economic Journal 100 (1990), 464-77.

Arrow, K. J., Social Choice and Individual Values (New-York: Wiley, 1951).

Bergstrom, T. C., L. E. Blume, and H. R. Varian, "On the Private Provision of Public Goods," Journal of Public Economics 29 (1986), 25-49.

Buckley, E., and R. T. A. Croson, "Income and Wealth Heterogeneity in the Voluntary Provision of Linear Public Goods," Journal of Public Economics 90 (2006), 935-55.

Chan, K. S., S. Mestelman, R. Moir, and R. A. Muller, "The Voluntary Provision of Public Goods under Varying Income Distributions," The Canadian Journal of Economics 29 (1996), 54-69. 
Chan, K. S., S. Mestelman, R. Moir, and R. A. Muller, "Heterogeneity and the Voluntary Provision of Public Goods," Experimental Economics 2 (1999), 530 .

Cherry, T. L., S. Kroll, and J. F. Shogren, "The Impact of Endowment Heterogeneity and Origin on Public Good Contributions: Evidence from the Lab," Journal of Economic Behavior \& Organization 57 (2005), 357-65.

Croson, R. T. A., "Partners and Strangers Revisited," Economics Letters 53 (1996), 25-32.

Fehr, E., and K. M. Schmidt, "A Theory of Fairness, Competition, and Cooperation," The Quarterly Journal of Economics 114 (1999), 817-68.

Fischbacher, U., "z-Tree: Zurich Toolbox for Ready-made Economic Experiments," Experimental Economics 10 (2007), 171-78.

Goodin, R. E., "Laundering Preferences," in J. Elster and A. Hylland, eds., Foundations of Social Choice Theory (Cambridge: Cambridge University Press, 1986).

Harsanyi, J. C., "Cardinal Welfare, Individualistic Ethics, and Interpersonal Comparisons of Utility," Journal of Political Economy 63 (1955), 309-21.

Hofmeyr, A., J. Burns, and M. Visser, "Income Inequality, Reciprocity and Public Good Provision: An Experimental Analysis," South African Journal of Economics 75 (2007), 508-20.

Isaac, M. R., and J. M. Walker, "Communication and Free-Riding Behavior: The Voluntary Contribution Mechanism," Economic Inquiry 26 (1988), 585-608.

Keser, C., "Voluntary Contributions to a Public Good When Partial Contribution is a Dominant Strategy," Economics Letters 50 (1996), 359-66.

Uler, N., "Public Goods Provision, Inequality and Taxes," Experimental Economics 14 (2011), 287-306.

Warr, P. G., "The Private Provision of a Public Good is Independent of the Distribution of Income," Economics Letters 13 (1983), 207-11. 
Willinger, M., and A. Ziegelmeyer, "Strength of the Social Dilemma in a Public Goods Experiment: An Exploration of the Error Hypothesis," Experimental Economics 4 (2001), 131-44.

Zelmer, J., "Linear Public Goods Experiments: A Meta-Analysis," Experimental Economics 6 (2003), 299-310. 